\title{
APEX ADVANCED FERRITIC STEEL, FLIBE SELF-COOLED FIRST WALL AND BLANKET DESIGN
}

\author{
by \\ C.P.C. WONG, S. MALANG, M. SAWAN, I. SVIATOSLAVSKY, \\ E. MOGAHED, S. SMOLENTSEV, S. MAJUMDAR, B. MERRILL, \\ R. MATTAS, M. FRIEND, J. BOLIN, S. SHARAFAT
}




\section{DISCLAIMER}

This report was prepared as an account of work sponsored by an agency of the United States Government. Neither the United States Government nor any agency thereof, nor any of their employees, makes any warranty, express or implied, or assumes any legal liability or responsibility for the accuracy, completeness, or usefulness of any information, apparatus, product, or process disclosed, or represents that its use would not infringe privately owned rights. Reference herein to any specific commercial product, process, or service by trade name, trademark, manufacturer, or otherwise, does not necessarily constitute or imply its endorsement, recommendation, or favoring by the United States Government or any agency thereof. The views and opinions of authors expressed herein do not necessarily state or reflect those of the United States Government or any agency thereof. 


\title{
APEX ADVANCED FERRITIC STEEL, FLIBE SELF-COOLED FIRST WALL AND BLANKET DESIGN
}

\author{
by \\ C.P.C. WONG, S. MALANG, ${ }^{*}$ M. SAWAN, ${ }^{\dagger}$ I. SVIATOSLAVSKY, ${ }^{\dagger}$ \\ E. MOGAHED, ${ }^{\dagger}$ S. SMOLENTSEV, ${ }^{\ddagger}$ S. MAJUMDAR, B. MERRILL, \\ R. MATTAS, ${ }^{\circ}$. FRIEND, J. BOLIN, S. SHARAFAT ${ }^{\ddagger}$
}

This is a preprint of a paper to be presented at the 11th International Conference on Fusion Reactor Materials, Kyoto, Japan, December 7-12, 2003 to be published in the Proceedings.

"Fusion Nuclear Technology Consulting, Linkenheim, Germany

tUniversity of Wisconsin, Madison, Wisconsin

FUniversity of California, Los Angeles, California

${ }$ Argonne National Laboratory, Argonne, Illinois

SINEEL, Idaho Falls, Idaho

Work supported by

the U.S. Department of Energy

under Contract No. DE-AC03-98ER54411

GENERAL ATOMICS PROJECT 30007

NOVEMBER 2003 


\begin{abstract}
As an element in the U.S. Advanced Power Extraction (APEX) program, we evaluated the design option of using advanced nanocomposite ferritic steel (AFS) as the structural material and Flibe as the tritium breeder and coolant. We selected the recirculating flow configuration as our reference design. Based on the material properties of AFS, we found that the reference design can handle a maximum surface heat flux of $1 \mathrm{MW} / \mathrm{m}^{2}$, and a maximum neutron wall loading of $5.4 \mathrm{MW} / \mathrm{m}^{2}$, with a gross thermal efficiency of $47 \%$, while meeting all the tritium breeding and structural design requirements. This paper covers the results of the following areas of evaluation: materials selection, first wall and blanket design configuration, materials compatibility, components fabrication, neutronics analysis, thermal hydraulics analysis including MHD effects, structural analysis, molten salt and helium closed cycle power conversion system, and safety and waste disposal of the recirculating coolant design.
\end{abstract}




\section{INTRODUCTION}

The U.S. DOE initiated the Advanced Power Extraction (APEX) program in 1997. The goal of the evaluation is to search for designs that can handle high volumetric power density and surface heat-flux, with assurance of fuel self-sufficiency, high thermal efficiency and passive safety and high availability for a tokamak power reactor [1]. We initiated the evaluation of concepts using advanced nanocomposite ferritic steel, 12YWT (AFS) as the structural material and Flibe as the tritium breeder and coolant. Design limits for this combination of materials were determined, and after an evaluation of different proposed first wall and blanket (FW/blanket) configurations, the recirculating flow configuration was selected as the reference design for more detailed evaluation. In 2003, we completed the evaluation of the AFS/Flibe FW/blanket concept. A summary of this design is presented. 


\section{MATERIALS SELECTION}

Fusion reactor designers have been struggling to find the right high performance combination of FW/blanket materials. Many requirements and properties are to be considered, and some of them are thermal and physical properties, operational temperature limits, activation, radiation damage, corrosion and compatibility with coolants and neutron multipliers, electrical properties, MHD effects, safety, tritium confinement and reliability.

\subsection{STRUCTURAL MATERIAL}

Ferritic/martensitic steels have been considered as prime candidates for fusion. However, these materials have an upper temperature limit of $550^{\circ} \mathrm{C}$ to $600^{\circ} \mathrm{C}$. One way suggested to increase this limit, which is obtained through microstructures that contain a high density of small particles of $\mathrm{Y}_{2} \mathrm{O}_{3}$ or $\mathrm{TiO}_{2}$ dispersed in a ferritic matrix. Such oxide dispersion strengthened (ODS) steel developed by ORNL is designated 12YWT [2]. This material has an upper temperature limit of $800^{\circ} \mathrm{C}$ and is compatible with Flibe up to $700^{\circ} \mathrm{C}$ [3]. Creep strength of the material is another important criterion in selecting the structural material. Creep rupture tests for 12 YWT have shown it to be vastly superior to other ODS steels [3].

\subsection{COOLANT}

The selected coolant material for use is molten salt $\mathrm{LiF}_{2} \mathrm{BeF}_{2}$ (Flibe). The use of Flibe as breeder and coolant enables simple self-cooled blanket designs without the need for electrical insulators between coolant and walls since the electrical conductivity of this molten salt is orders of magnitudes lower than that of lead-lithium or lithium. However, for a high performance Flibe coolant design, we will have to overcome a number of obstacles. We will have to design to its exceptionally low thermal conductivity at $1 \mathrm{~W} / \mathrm{mK}$, high kinematic viscosity at $11.5 \times 10^{-6} \mathrm{~m}^{2} / \mathrm{s}$, and the need of additional neutron multiplier. In addition, Flibe is rather aggressive to a number of candidate structural materials with the formation of hydrogen fluoride (HF). Therefore, the control of the formation of HF in the Flibe stream will also be needed, which can be done externally to the FW/blanket volume.

\subsection{NEUTRON MULTIPLIER}

From a nuclear performance point of view, beryllium is the best neutron multiplier. However, inherent problems of radiation damage and the generation and accumulation of tritium are potential concerns. To avoid these problems, we have selected $\mathrm{Pb}$ as our reference neutron multiplier, which has a melting point of $327^{\circ} \mathrm{C}$. 


\subsection{COMPATIBILITY}

Two issues of material compatibility are predominant in this combination of materials. They are the compatibility of $12 \mathrm{YWT}$ with Flibe and with $\mathrm{Pb}$. Based on experiments at ORNL [3], the maximum temperature at which ODS ferritic steel can be used with Flibe was set at $700^{\circ} \mathrm{C}$. For pure $\mathrm{Pb}$ and lead-bismuth, the primary corrosion mechanism is the dissolution of the structural material. This can be prevented by the formation of an adherent stable oxide film by adding oxygen to the molten $\mathrm{Pb}$. The temperature window for maintaining this layer is very small. The recommended temperature limit based on dynamic corrosion tests was set at $620^{\circ} \mathrm{C}$. However, since the $\mathrm{Pb}$ in this design is circulated at a semistatic rate, it was felt that $700^{\circ} \mathrm{C}$ might be acceptable [4]. Another possibility is the use of Wcoating to separate the Flibe and AFS surfaces. 


\section{RECIRCULATING FLOW CONFIGURATION}

For the selection of FW/blanket configuration, we have two conflicting requirements for the self-cooled Flibe blanket. We will need to remove high surface heat flux, which prefers low coolant temperature, but at the same time we desire high blanket outlet coolant temperature for a high power conversion system. After studying several different FW/blanket flow configurations, we selected the recirculating flow scheme as shown in Fig. 1. This flow configuration allows the coolant mass flow rate in the FW channels to be considerably higher than the flow rate to the power conversion system, which can be achieved by employing a bypass to the flow in the large central channel leaving the blanket segments as shown. In Fig. 1, a pump is arranged at the inlet to the blanket,
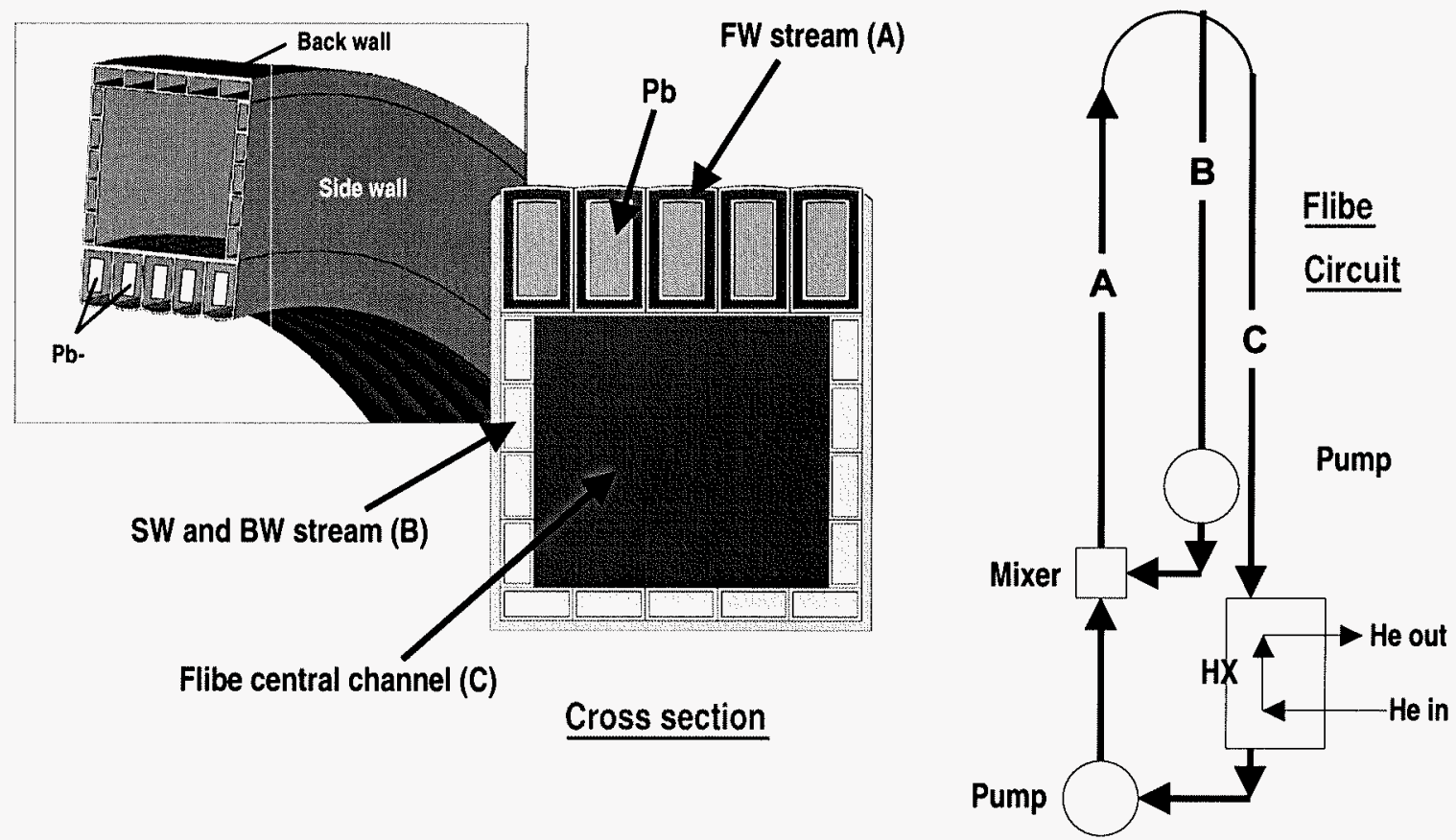

Fig. 1. Schematics of the AFS/Flibe FW/blanket design. (The left side shows the 3-D poloidal schematic and a cross-section of the FW/blanket and the right side shows the recirculating flow circuit diagram.)

pushing the coolant stream A from the bottom through the FW/multiplier region. At the top of the blanket, the coolant stream is divided into a bypass stream B and an exit stream C, flowing to the heat exchanger of the power conversion system. There is a second pump arranged controlling the split between exit flow $\mathrm{C}$ and bypass flow $\mathrm{B}$. Both coolant streams are mixed after the heat exchanger $(\mathrm{HX})$ and the coolant temperature at the blanket exit, as well as the one at the blanket inlet, depends on the mixing ratio. This flow configuration allows a FW inlet temperature considerably higher than the minimum Flibe temperature after 
the $\mathrm{HX}$, and a higher velocity and heat transfer coefficient in the FW cooling channels when compared to a typical once-through flow scheme. Figure 1 also presents a mid-plane element cross-section of $0.3 \mathrm{~m}$ in the toroidal direction and $0.3 \mathrm{~m}$ in radial direction. These dimensions were determined by reactor systems and thermal parametric studies which resulted in our reference design with the capability of removing a maximum surface heat flux of $1 \mathrm{MW} / \mathrm{m}^{2}$ and neutron wall loading of $5.4 \mathrm{MW} / \mathrm{m}^{2}$. 


\section{NEUTRONICS ANALYSIS}

Neutronics calculations were performed to determine the relevant nuclear performance parameters for the blanket with Flibe coolant and lead multiplier. These include tritium breeding, nuclear heating, radiation damage, and shielding requirements. The material composition of each radial FW/blanket zone is utilized. In the outboard $(\mathrm{OB})$ side, the recirculating blanket is followed by a $40 \mathrm{~cm}$ thick secondary blanket consisting of $94 \%$ Flibe and $6 \%$ AFS structure. Due to limited space, no secondary blanket is utilized in the inboard (IB) region. The ONEDANT module of the DANTSYS 3.0 discrete ordinates particle transport code system [5] was used to perform the calculations utilizing the FENDL-2 [6] nuclear data library. Both the IB and OB regions were modeled simultaneously to account for the toroidal effects. The results were normalized to the peak neutron wall loading values of 5.45 and $3.61 \mathrm{MW} / \mathrm{m}^{2}$ in the $\mathrm{OB}$ and IB regions, respectively. Assuming neutron coverage of $75 \%$ for the OB region, $15 \%$ for the IB region, and $10 \%$ for the divertor region, at $40 \%$ ${ }^{6} \mathrm{Li}$ enrichment, the overall TBR will be $\sim 1.11$ excluding breeding in the divertor region. Breeding in the divertor zone could add $\sim 0.05$ depending on the amount of Flibe used. We expect that tritium self-sufficiency of a power reactor can be realized with this FW/blanket design. The total nuclear energy multiplication in the $30 \mathrm{~cm}$ thick recirculating IB and $\mathrm{OB}$ blankets and $40 \mathrm{~cm}$ thick $O B$ secondary blanket is 1.13 . The peak radiation damage parameters in the OB AFS structure were calculated per full power year (FPY) at $77.6 \mathrm{dpa} / \mathrm{FPY}$ and $955 \mathrm{He}$ at. ppm/FPY. Based on a radiation damage limit of $200 \mathrm{dpa}$, the lifetime of the recirculating blanket is expected to be $\sim 3$ FPY. The peak cumulative end-oflife (30 FPY) dpa of the OB secondary blanket is $60.3 \mathrm{dpa}$ implying that it will be a lifetime component. All shielding zones will be lifetime components also.

Calculations were performed to determine the radial build in both the IB and OB regions required to provide adequate shielding for the vacuum vessel (VV) and TF magnet coils. The peak end-of-life helium production in the VV is 0.4 at. $\mathrm{ppm}$, which would allow for rewelding. The peak values of end-of-life fast neutron fluence and insulator dose in the superconducting magnet are $2.4 \times 10^{18} \mathrm{n} / \mathrm{cm}^{2}$ and $4.4 \times 10^{9} \mathrm{rad}$, which are below the widely accepted limits of $10^{19} \mathrm{n} / \mathrm{cm}^{2}$ for $\mathrm{Nb}_{3} \mathrm{Sn}$ and $10^{10} \mathrm{rad}$ for polyimides, respectively.

Activation calculations were performed for the reference recirculating blanket design. Results show that the AFS structure dominates the total activity and decay heat. To qualify as low level class $\mathrm{C}$ waste, the Mo content of AFS needs to be reduced from $0.02 \%$ to $<0.01 \%$ in weight. In addition, an attempt should also be made to eliminate or limit concentration of impurities such as $\mathrm{Nb}$ and $\mathrm{Ag}$ to less than about $1 \mathrm{wppm}$. While the waste disposal rating (WDR) of the Flibe is well below unity, the WDR for stagnant $\mathrm{Pb}$ is $\sim 50$ implying that it has 
to be circulated at a flow rate $\left(<1 \mathrm{~cm}^{3} / \mathrm{s}\right)$ to remove the generated ${ }^{208} \mathrm{Bi}$ and allow $\mathrm{Pb}$ disposal as low level waste also. 


\section{THERMAL HYDRAULICS}

One of the reasons for the selection of Flibe as the FW/blanket coolant is the much lower electrical conductivity as compared to lithium. However, in order to assess the thermalhydraulics of this design, we have to take MHD effects into account. We performed an assessment to qualify and quantify the MHD effects related to the Flibe flow in the recirculating blanket under a strong inboard and outboard magnetic field of 4.3 to $7.8 \mathrm{~T}$, respectively, and to give directions for calculating the MHD pressure drop in the subsequent thermal-hydraulics analysis at different locations of the FW/blanket design. Three related issues were taken into consideration. They are the turbulence suppression by a magnetic field, effect of the magnetic field on heat transfer, and MHD pressure drop. We learned that in the presence of electrically conducting walls, the MHD effects, especially those related to turbulence suppression, are not negligible and should be evaluated. Formulas from the literature and 2-D computer code were then used to assess the MHD pressure drops for both the inboard and outboard subchannels. Pressure drop scaling coefficients were generated for the thermal analysis at different subchannel elements for the inboard and outboard blankets [7].

The reference FW design utilizes rectangular channels as shown in Fig. 1. To optimize the thermal hydraulics design while accounting for the surface heat flux and volumetric power generation from the structure, lead multiplier and the Flibe coolant, we varied the eccentricity location of the $\mathrm{Pb}$ tubes in the $\mathrm{FW}$ channels for the outboard and inboard modules. The FW channel dimensions were optimized to maintain uniform pressure drop (including $\mathrm{MHD}$ pressure drop) and uniform Flibe temperature around the $\mathrm{Pb}$ multiplier tube. We then determined the FW thermal hydraulics parameters (pressure drop, velocities, temperatures) for the reference rectangular FW channels design. Using eccentrically located lead tubes in the FW design results in larger cooling subchannels at the front and smaller ones at the back. For the same pressure drop, the flow velocity will be larger with higher heat transfer coefficient at the front where a larger heat load needs to be removed. The selected $\mathrm{Pb}$ tube has an eccentricity of $3.57 \mathrm{~mm}$ for the outboard blanket. In addition, the eccentric configuration enhances the Flibe temperature uniformity around the $\mathrm{Pb}$ tube. This has the advantage of reducing the expected thermal stresses. With this optimization, at an outboard magnetic field strength of $\sim 4.3 \mathrm{~T}$, the total outboard FW/blanket pressure drop, including $\mathrm{MHD}$ and frictional, is $1.03 \mathrm{MPa}$. The maximum interface temperature between the Flibe and $\mathrm{FW}$ steel is $667^{\circ} \mathrm{C}$ and the maximum interface temperature between lead and steel is $680^{\circ} \mathrm{C}$, which are below the design limit of $700^{\circ} \mathrm{C}$ for both cases. Similar calculations were performed for the inboard FW tubes. The total inboard FW/blanket pressure drop is $0.88 \mathrm{MPa}$. The maximum interface temperature between the Flibe and FW 
steel is $686^{\circ} \mathrm{C}$ and the maximum interface temperature between lead and steel is $652^{\circ} \mathrm{C}$. For both outboard and inboard designs, results show that the maximum first wall temperatures everywhere can be designed to lower than the design limit of $800^{\circ} \mathrm{C}$. 


\section{STRESS ANALYSIS}

Heat conduction and stress analysis were carried out for this FW/blanket design using the finite element program ABAQUS [8]. The reference cross-section in Fig. 1 was used and the stress analysis was conducted with the generalized plane strain assumption. We calculated the time-independent primary stress allowable $S_{m}$ and the time-dependent primary stress allowable $S_{t}$. The primary stress limits for the membrane $\left(P_{m}\right)$ and membrane plus bending $\left(\mathrm{P}_{\mathrm{L}}+\mathrm{P}_{\mathrm{b}}\right)$ were determined. We found that the stresses in the blanket at the bottom, midplane, and top are within the prescribed limits. We also found that the design also meets cycling ratcheting criteria by meeting the primary plus secondary stress limit for cyclic ratcheting, which is the A2 test of the ITER Structural Design Criteria (ISDC) [9]. 


\section{FABRICATION}

The AFS that we selected is an ODS ferritic alloy. Thus far, the only joining method that seems to work is diffusion bonding with the contact pressure provided by HIPing. As can be seen from Fig. 1, the FW/blanket configuration is fairly complicated. Two methods of fabrication have been considered, both use preliminary welding in preparation to diffusion bonding. In the first method, the back plate, with the $\mathrm{Pb}$ channels already attached, is welded in one piece around the perimeter. In the second method, a strip of plate with the $\mathrm{Pb}$ tube attached is welded first to each individual channel. Then the FW channels are lined up in the toroidal direction and diffusion bonded to a back plate [10]. These fabrication methods seem reasonable at this stage of development, but further development and demonstration will be needed in the future. 


\section{POWER CONVERSION SYSTEM}

With the Flibe coolant inlet/outlet temperatures at $500^{\circ} \mathrm{C} / 681^{\circ} \mathrm{C}$, we have selected the 2 turbines and 4 compressors molten salt coolant gas cycle (MCGC) turbine [11] design with each turbine handling $800 \mathrm{MW}_{\text {th }}$ with a gross thermal efficiency of $46.9 \%$. For the reactor design, we will need two of these power conversion systems to handle the total thermal power of $3200 \mathrm{MW}_{\mathrm{th}}$, leading to a gross electrical power output of $1500 \mathrm{MW}_{\mathrm{e}}$. 


\section{SAFETY ASSESSMENT}

The solubility of tritium in Flibe is exceptionally low, while the solubility of tritium in the AFS is relatively high, resulting in a high tritium partial pressure over this fluid and high tritium permeation rate through the AFS blanket and primary piping walls. With a continuous extraction of tritium from the halo helium cover gas around the Flibe coolant system, and with the choice of Brayton cycle, we found that the design can be operated within allowable tritium release limits for routine releases to the air of the confinement building and to the cooling water of the Brayton cycle. A further reduction to easily tolerable values is possible in the Brayton cycle if aluminum alloy tubes are used in the heat exchanger. We explored some of the safety issues. In particular, we examined the site boundary dose during a worst-case (frequency $<10^{-6}$ per year) confinement-boundary-bypass accident, which was a consequence of a total loss-of-site power accident with an induced plasma disruption that breaks the windows of a diagnostic port or plasma-heating duct, causing an air-ingress to occur into the VV. The MELCOR code $[12,13]$ was used for the analysis of this accident. Once the FW temperature drops below $800^{\circ} \mathrm{C}$, which occurs within two days, the FW aerosol oxidation rate becomes very low. From radiological dose calculations $[12,13]$, the dose for stack releases of tritium as HTO is $77 \mathrm{mSv} / \mathrm{kg}$, assuming a $1-\mathrm{km}$ site boundary and worst-case weather conditions. The specific dose of Flibe is $0.32 \mathrm{mSv} / \mathrm{kg}$, with $99 \%$ of the dose due to F-18. The major contributors to the FW AFS oxide specific dose are $\mathrm{Mn}-54, \mathrm{Ca}-45$, and $\mathrm{Ti}-45$. Given the rate of release from this design of tritium, Flibe aerosols, and FW AFS oxide aerosols, the facility must be isolated within four weeks to stay below the $10 \mathrm{mSv}$ non-evacuation plan regulatory site limit. 


\section{CONCLUSIONS AND RECOMMENDATIONS}

The results of the high performance AFS/Flibe/ $\mathrm{Pb}$ FW/blanket design look promising. With the recirculating flow configuration, the design allows the control of the first wall coolant heat transfer and maintains high coolant outlet temperature. The design can handle a maximum surface heat flux of $1 \mathrm{MW} / \mathrm{m}^{2}$, and a neutron wall loading of $5.4 \mathrm{MW} / \mathrm{m}^{2}$. Using the MCGC system as the power conversion system, a gross thermal efficiency of $47 \%$ can be projected. The overall tritium breeding ratio is 1.11 excluding breeding in the divertor region. Including $\mathrm{MHD}$ effects on the Flibe coolant and with the adjustment on the radial location of the $\mathrm{Pb}$ channel, we found that the pressure drop can be adjusted to an acceptable value while designing to various materials temperature limits. Structural analysis results show that the maximum thermal stress occurs at the midplane of the blanket, and the design would satisfy the primary plus secondary stress limits including cyclic ratcheting according to the ITER structural design criteria. Since this AFS is a developmental ODS ferritic alloy, we found that diffusion bonding could be a means of fabrication and two methods of fabrication are proposed. Safety assessment of the design shows that, with a continuous extraction of tritium from the halo helium cover gas, the design can be operated within the allowable tritium release limit. Under the worst case confinement-bypass accident, given the rate of release from this design, the facility can be operated to meet the limit of not requiring a site evacuation plan as long as the facility can be isolated within four weeks. For this high performance AFS/Flibe/Pb FW/blanket design, a few needed developments have been stated in this paper. However, critical issues for this design are mainly related to the developmental nanocomposite AFS. Not only do the projected structural design properties need to be further verified, the allowable interface temperatures between AFS/Flibe and AFS/Pb will have to be confirmed also. 


\section{ACKNOWLEDGMENT}

This report of work was supported by the U.S. Department of Energy under Contract No. DE-AC03-98ER54411. 


\section{REFERENCES}

[1] M.A. Adbou, "Exploring novel high power density concepts for attractive fusion systems," Fusion Eng. and Design 45 (1999) 145.

[2] R.L. Klueh, P.J. Maziasz, I.S. Kim, L. Heatherly, D.T. Hoelzer, N. Hashimoto, E.A. Kenik and K. Miyahara, "Tensile and creep properties of an oxide dispersionstrengthened ferritic steel," J. Nucl. Mater. 307-311 (2002) 773.

[3] S. J. Zinkle, Private communication, 2001.

[4] A. Lopatkin., Personal communication, 2002.

[5] R.E. Alcouffe, et al., "DANTSYS 3.0, a diffusion accelerated neutral particle transport code system," Los Alamos National Laboratory Report LA-12969-M (1995).

[6] M. Herman and H. Wienke, "FENDL/MG-2.0 and FENDL/MC-2.0, the processed cross-section libraries for neutron-photon transport calculations," International Atomic Energy Agency Report IAEA-NDS-176 (1997).

[7] C.P.C. Wong, S. Malang, M. Sawan, I. Sviatoslavsky, E. Mogahed, S. Smolentsev, S. Majumdar, B. Merrill, R. Mattas, M. Friend, J. Bolin, S. Sharafat, "Molten salt selfcooled solid first wall and blanket design based on advanced ferritic steel," Fusion Eng. and Design to be published (2003).

[8] Computer code ABAQUS (Version 6.3) (Hibbitt, Karlsson, and Sorensen, Inc., 2002).

[9] ITER structural design criteria for in-vessel components (ISDC), ITER Report IdoMSS74MA1 97-12-12 R0.2 (1998).

[10] I. Sviatoslavsky, S. Mogahed, R. Majumdar, S. Mattas, P. Malang, M. Fogartym, M. Friend, C, Wong, S. Sharafat, "Solid wall recirculating blanket: geometry, materials, materials compatibility, structural evaluation, fabrication and fluid circuits," Fusion Eng. and Design to be published (2003).

[11] P.F. Peterson, "Multiple-reheat brayton cycles for nuclear power conversion with molten salt coolants," to be published in Nucl. Technology (2003).

[12] M. Abbott, "Revised results - MACCS2 doses for fusion isotopes release to the atmosphere using P-G dispersion parameters," an INEEL letter to D.A. Petti, MLA-1199, April 14, 1999.

[13] B. Merrill, M. Sawan, C.P.C. Wong, L.C. Cadwallader, S. Malang, D.K. Sze, "Safety assessment of APEX advanced ferritic steel molten salt blanket design concepts," to be published in Fusion Eng. and Design. 